\title{
Effects of berberine on a rat model of chronic stress and depression via gastrointestinal tract pathology and gastrointestinal flora profile assays
}

\author{
XIAOHUI ZHU ${ }^{1,2}$, YANGDONG SUN ${ }^{3}$, CHENGGANG ZHANG $^{2}$ and HAIFENG LIU ${ }^{1,2}$ \\ ${ }^{1}$ Department of Gastroenterology, General Hospital of the Chinese People's Armed Police Forces, Beijing 100039; \\ ${ }^{2}$ Beijing Institute of Radiation Medicine, State Key Laboratory of Proteomics, Cognitive and \\ Mental Health Research Center of PLA, Beijing 100850; ${ }^{3}$ Department of Biological Engineering, \\ College of Pharmacy, Jilin University, Jinan, Shandong 130021, P.R. China
}

Received November 9, 2015; Accepted November 10, 2016

DOI: $10.3892 / \mathrm{mmr} .2017 .6353$

\begin{abstract}
Chronic stress and depression are challenging conditions to treat, owing to their complexity and lack of clinically available and effective therapeutic agents. The aim of the present study was to investigate the mechanism by which berberine acts, by examining alterations to gastrointestinal tract histopathology and flora profile in a rat model, following the induction of stress. Research associating gastrointestinal flora and depression has increased, thus, the present study hypothesized that stress induces depression and changes in the gastrointestinal system. The chronic mild stress rat model was previously established based on a set of 10 chronic unpredictable stress methods. In the present study, the measurements of body weight, behavior, gastrointestinal tract histopathology and gastrointestinal flora profile were collected in order to elucidate understanding of chronic stress and depression in this region. In the present study, induced stress and the resulting depression was demonstrated to significantly decrease the body weight and sucrose preference of rats, as well as significantly increasing traverse time, vertical movement time, grooming time and motionless time in an open-field test. Following modeling and subsequent treatment with low or high doses of berberine, the measurements were significantly different when compared with unstressed rats. Berberine appears to reverse the physical damage brought about by stress within the gastric mucosa
\end{abstract}

Correspondence to: Dr Haifeng Liu, Department of Gastroenterology, General Hospital of the Chinese People's Armed Police Forces, 69 Rongding Road, Haidian, Beijing 100039, P.R. China

E-mail: haifengliu333@163.com

Key words: chronic stress depression model, berberine, histopathology, gastrointestinal flora, enterobacterial repetitive intergenic consensus sequence-based polymerase chain reaction, profile, protection and intestinal microvilli of the stomach, ileum, cecum and colon. Using enterobacterial repetitive intergenic consensus sequence-based polymerase chain reaction analysis, several distinctive bands disappeared following modeling; however, novel distinctive bands appeared in response to the graded berberine treatment. In conclusion, the present study identified that high concentrations of berberine markedly protects rats from various symptoms of chronic stress and depression, with the potential of facilitating treatment within clinical practice.

\section{Introduction}

Stress is a systemic non-specific adaptive response, and is characterized as an inappropriate response to a variety of stimuli generated by environmental and psychological factors. These stimuli are divided into acute and chronic stress, according to the duration and intensity of episodes (1-4). Acute stress is a condition lasting between several min and h, whereby the body suffers a rapid and severe psychological trauma. In addition, it is characterized by a psychomotor excitement with a heightened response to fear and behavior blindness. These symptoms disappear following the removal of the stimulus (5-8). By contrast, chronic stress is a response of body to long-duration, uncontrollable emotional pressure, and presentation of high blood pressure, muscle tissue damage, growth inhibition, immune system suppression and metal health damage (9-12). The disease has been become a common issue clinically as a result of its complexity (13-15).

Numerous individuals become plagued with a variety of stresses in day-to-day life that risk damaging wellbeing, which, if not correctly treated, frequently leads to diagnoses of depression and chronic stress (13-18). As a common and multifactorial condition, depression exhibits the characteristics of repeated attack, not only affecting the patient, but also having an impact on those surrounding the patient (19-21). The gastrointestinal digestive system is the most susceptible system to environmental effectors, particularly the gastrointestinal tract and gastrointestinal flora, and it is easily disturbed when subjected to surrounding aversive stimuli (22-26). 
The present study used a rat model of chronic stress and depression $(16,27)$ to investigate the gastrointestinal tract histopathology and gastrointestinal flora profile. As a result of the previously identified antidepressant and neuroprotective effects of berberine on neurodegenerative disorders, it was hypothesized that it may have implications on the treatment on chronic stress and depression.

\section{Materials and methods}

Establishment of rat chronic stress depression model and drug intervention. A total of 60 adult specific pathogen-free Sprague Dawley rats (male; weight, 200-220 g; age, 2 months) were purchased and raised at the Laboratory Animal Center of the Academy of Military Medical Sciences of the People's Liberation Army (Beijing, China). They were maintained at $25 \pm 2^{\circ} \mathrm{C}$ in a humidity of $40-60 \%$ under a 12 -h light/dark cycle. The rats were randomly divided into the following six groups ( $n=10 /$ group): Normal group (regularly breeding), model group (subject to 10 stress approaches, according to the previous literature on chronic unpredictable stress), low berberine group (40 mg/kg/day), high berberine group (200 mg/kg/day), bifidobacterium group (140 mg/kg/day) and fluoxetine group ( $2 \mathrm{mg} / \mathrm{kg} / \mathrm{day})$. The aforementioned 10 stress approaches $(16,27)$ included fasting for $24 \mathrm{~h}$, water deprivation for $24 \mathrm{~h}$, tail nipping ( $1 \mathrm{~cm}$ from end of tail) for $5 \mathrm{~min}$, day and night inversion for $24 \mathrm{~h}, 4^{\circ} \mathrm{C}$ cold water swimming for $5 \mathrm{~min}, 45^{\circ} \mathrm{C}$ environment for $5 \mathrm{~min}$, damp bedding for $24 \mathrm{~h}, 45^{\circ}$ sloping of floor for $24 \mathrm{~h}$, behavior constraint for $4 \mathrm{~h}$ and horizontal vibrating $(60 \mathrm{~Hz})$ for $45 \mathrm{~min}$. One method was selected daily and the interval between similar stress approaches was at least 7 days. Prior to modeling with each chronic unpredictable stress method, the rats were treated with either $2 \mathrm{ml}$ of a low concentration of berberine $(40 \mathrm{mg} / \mathrm{kg} /$ day $)$, a high concentration of berberine (200 mg/kg/day), bifidobacterium (140 mg/kg/day) or fluoxetine $(2 \mathrm{mg} / \mathrm{kg} / \mathrm{day})$. The normal and model groups were treated with an equal volume $(2 \mathrm{ml})$ of $0.9 \%$ saline. The rat body weights were recorded and the rats were subsequently subjected to an open field test, forced swimming test and sucrose preference test. The present study was approved by the Ethics Committee of the Academy of Military Medical Sciences of the People's Liberation Army.

\section{Behavioral evaluation}

Open field test. The open field test was performed in a quiet and dark environment, and rat behavior was examined prior to and following modeling. The rats were placed in a homemade open field box (opaque; height, $40 \mathrm{~cm}$; base, $80 \times 80 \mathrm{~cm}$ ) that was equally divided into 25 squares, left uncovered at the top and painted black inside. Each test lasted $5 \mathrm{~min}$ for each measurement. The three measurements collected included traversing time, vertical movement and grooming times. These data were followed up using statistical analysis.

Forced swimming test. Prior to the forced swimming test, the rats were placed into a homemade forced swimming cylinder (diameter, $30 \mathrm{~cm}$; height, $30 \mathrm{~cm}$; water temperature, $23 \pm 2^{\circ} \mathrm{C}$; water depth, $25 \mathrm{~cm}$ ) and were preconditioned for $15 \mathrm{~min}$ prior to having excess water removed with a towel. After $24 \mathrm{~h}$, forced
Table I. Alterations to rat body weight prior to and after modeling.

\begin{tabular}{llc}
\hline Group & $\begin{array}{c}\text { Prior to modeling } \\
(\mathrm{n}=10)(\mathrm{g})\end{array}$ & $\begin{array}{c}\text { After modeling }) \\
(\mathrm{n}=10)(\mathrm{g})\end{array}$ \\
\hline Normal & $232.64 \pm 7.6539$ & $440.91 \pm 13.1597$ \\
Model & $233.79 \pm 9.0775$ & $323.39 \pm 19.6040^{\mathrm{a}}$ \\
Low berberine & $237.08 \pm 12.7968$ & $385.11 \pm 23.8284^{\mathrm{a}}$ \\
High berberine & $235.31 \pm 12.9071$ & $395.67 \pm 18.2214^{\mathrm{a}}$ \\
Bifidobacterium & $234.91 \pm 9.5875$ & $385.75 \pm 21.1776^{\mathrm{a}}$ \\
Fluoxetine & $235.59 \pm 10.7508$ & $389.43 \pm 25.5993$ \\
\hline
\end{tabular}

Data are presented as the mean \pm standard deviation ( ${ }^{\mathrm{a}} \mathrm{P}<0.01$ vs. the normal group).

swimming was recorded for $6 \mathrm{~min}$, followed by recording the motionless time for $4 \mathrm{~min}$. Motionless time was characterized as rats stopping thrashing in the water, where their limbs had a slight motion in order to keep afloat.

Sucrose preference test. Prior to performing the sucrose preference test, the rats were divided into one per cage and fed an equal volume of $1 \%$ sucrose (two flasks, $200 \mathrm{ml} / \mathrm{flask}$ ) to precondition for $24 \mathrm{~h}$. Following $24 \mathrm{~h}$ water deprivation on day 28 , an equal volume of $1 \%$ sucrose and water (one flask in each, $200 \mathrm{ml} /$ flask) was fed to the rats, and the volume of residual liquid was measured in order to calculate the total liquid consumption, sucrose consumption and water consumption. The sucrose preference was calculated based on the formula: Sucrose preference $=$ (sucrose consumption/total liquid consumption)x $100 \%$. Subsequently, the rats underwent cervical dislocation and the stomach, ileum, cecum, colon and gastrointestinal contents were collected. The tissues of stomach, ileum, cecum and colon were sliced at a thickness of 3-5 $\mu \mathrm{m}$, and hematoxylin and eosin (H\&E) staining was performed. The different contents of the stomach, ileum, cecum and colon were separated, and the genomic DNA was extracted prior to analysis by enterobacterial repetitive intergenic consensus sequence-based-polymerase chain reaction (ERIC-PCR).

$H E$ staining. The slides were deparaffinized, rehydrated and frozen or vibratome sections were mounted on slides and rehydrated. The sections were stained with hematoxylin for $\sim 3-5 \mathrm{~min}$, depending on the thickness of the section and fixative (up to $20 \mathrm{~min}$ if the solution was not fully ripened), and excess stain was removed using tap water. The sections were destained for a few sec in acid alcohol until the sections appeared red. The sections were briefly rinsed in tap water to remove the acid. Sodium bicarbonate was applied for $\sim 2 \mathrm{~min}$ until the nuclei were clearly visible in blue. The H\&E-stained slides from the final rinse with tap water were placed in $70 \%$ ethanol for $3 \mathrm{~min}$, and then in eosin for $2 \mathrm{~min}$. The slides were subsequently submerged three times in $95 \%$ ethanol for $5 \mathrm{~min}$, prior to being transferred to absolute ethanol. The images were captured using a microscope connected to a CCD camera. 
Table II. Traversing, vertical and grooming times in an open-field test following modeling.

\begin{tabular}{lccc}
\hline Group & $\begin{array}{c}\text { Traversing time } \\
(\mathrm{sec} ; \mathrm{n}=10)\end{array}$ & $\begin{array}{c}\text { Vertical time } \\
(\mathrm{sec} ; \mathrm{n}=10)\end{array}$ & $\begin{array}{c}\text { Grooming time } \\
(\mathrm{sec} ; \mathrm{n}=10)\end{array}$ \\
\hline Normal & $114.50 \pm 6.9801$ & $22.20 \pm 4.0222$ & $3.70 \pm 0.8233$ \\
Model & $54.10 \pm 10.7647^{\mathrm{b}}$ & $7.50 \pm 1.4337^{\mathrm{b}}$ & $0.70 \pm 0.4830^{\mathrm{b}}$ \\
Low berberine & $53.80 \pm 11.3117^{\mathrm{b}}$ & $9.30 \pm 1.8886^{\mathrm{a}}$ & $1.80 \pm 0.7888^{\mathrm{b}}$ \\
High berberine & $84.30 \pm 11.5089^{\mathrm{b}}$ & $13.80 \pm 2.3944^{\mathrm{b}}$ & $2.70 \pm 0.6749^{\mathrm{b}}$ \\
Bifidobacterium & $69.10 \pm 10.4823^{\mathrm{a}}$ & $12.80 \pm 3.2249^{\mathrm{b}}$ & $2.60 \pm 0.6992^{\mathrm{b}}$ \\
Fluoxetine & $90.40 \pm 9.0086^{\mathrm{b}}$ & $14.70 \pm 2.4060^{\mathrm{b}}$ & $3.10 \pm 0.5676^{\mathrm{b}}$ \\
\hline
\end{tabular}

Data are presented as the mean \pm standard deviation $\left({ }^{\mathrm{a}} \mathrm{P}<0.05\right.$, ${ }^{\mathrm{b}} \mathrm{P}<0.01 \mathrm{vs}$. the normal group).

Extraction of gastrointestinal genomic DNA. The genomic DNA of the stomach, ileum, cecum and colon was extracted from rats using a genomic DNA Extraction kit (Promega Corporation, Madison, WI, USA), according to the manufacturer's protocol. A total of 180-200 mg tissue was weighed and mixed with $1.4 \mathrm{ml}$ GSL buffer (Promega Corporation) for $1 \mathrm{~min}$. Following this, the solution was incubated in a $70^{\circ} \mathrm{C}$ water bath, vortexed for $15 \mathrm{sec}$ and centrifuged at $12,000 \mathrm{x} \mathrm{g}$ at room temperature for $1 \mathrm{~min}$. The supernatant was removed and transferred to a $2 \mathrm{ml}$ eppendorf tube and an inhibitor adsorption piece was added for incubation for $1 \mathrm{~min}$ at room temperature, and this was centrifuged at $12,000 \mathrm{x} \mathrm{g}$ for $3 \mathrm{~min}$. The supernatant was removed and transferred to a $1.5 \mathrm{ml}$ eppendorf tube with an inhibitor adsorption piece to incubate for $1 \mathrm{~min}$ at room temperature, and was centrifuged at $12,000 \times \mathrm{g}$ for $3 \mathrm{~min}$. The supernatant was eluted and transferred into a $1.5 \mathrm{ml}$ eppendorf tube once again, and $15 \mu \mathrm{l}$ proteinase $\mathrm{K}$ and $200 \mu \mathrm{l}$ GB buffer were added and vortexed for $15 \mathrm{sec}$ prior to incubation in a $70^{\circ} \mathrm{C}$ water bath for $30 \mathrm{~min}$. A total of $200 \mu \mathrm{l}$ ethanol was added and the solution was vortexed, and subsequently transferred to a $\mathrm{CR}_{2}$ column (Promega Corporation), where it was centrifuged at $13,000 \mathrm{x}$ g for $30 \mathrm{sec}$ at room temperature to discard the centrifugate. A total of $500 \mu \mathrm{l}$ GD buffer (Promega Corporation, Madison, WI, USA) was added and centrifuged at $10,000 \mathrm{x} \mathrm{g}$ for $30 \mathrm{sec}$ at room temperature to discard the centrifugate. The $\mathrm{CR}_{2}$ column was transferred to a new collection tube and $50 \mu \mathrm{l}$ TB washing buffer (Promega Corporation) was added at room temperature for 2-5 min, and the samples were centrifuged at $10,000 \mathrm{x}$ g for $2 \mathrm{~min}$ at room temperature. The eluent was collected and its concentration was determined using ultraviolet spectrophotometry.

ERIC-PCR amplification of gastrointestinal flora profile. The extracted genomic DNA was used as a template to perform ERIC-PCR using the following primers: ERIC-1 (forward), 5'-ATGTAAGCTCCTGGGGATTCAC-3' and ERIC-2 (reverse), 5'-AAGTAAGTGACTGGGGTGAGCG-3'. The $25 \mu \mathrm{l}$ PCR reaction solution was prepared, as follows: $1 \mu 1$ genomic DNA, $0.125 \mu 1$ Ex Taq (5 U/ $\mu 1), 2.5 \mu 1$ 10X Ex Taq Buffer, $2 \mu \mathrm{l}$ dNTP, $0.5 \mu$ l ERIC-1 primer, 0.5 $\mu$ l ERIC-2

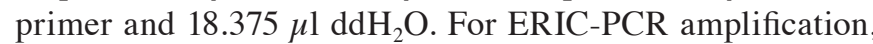
the PCR procedure was performed using the following steps: $95^{\circ} \mathrm{C}$ initial denaturation for $7 \mathrm{~min},\left(95^{\circ} \mathrm{C}\right.$ denaturation for
$30 \mathrm{sec}, 52^{\circ} \mathrm{C}$ annealing for $1 \mathrm{~min}, 65^{\circ} \mathrm{C}$ extension for $8 \mathrm{~min}$ for 30 cycles), then $65^{\circ} \mathrm{C}$ extension for $16 \mathrm{~min}$, with a $4^{\circ} \mathrm{C}$ hold. PCR products were identified using $1.5 \%$ agarose gel electrophoresis and images were captured using Lane 1D image software (version 2.0; Beijing SAGE Creation Science Co., Ltd., Beijing, China).

Statistical analysis. All data are expressed as the mean \pm standard deviation. Statistical analysis was performed with one-way analysis of variance using SPSS software (version 21.0; IBM SPSS, Armonk, NY USA), and Student's t-test was performed in a group of two samples. $\mathrm{P}<0.05$ and $\mathrm{P}<0.01$ were considered to indicate significant and highly significant statistical differences, respectively.

\section{Results}

Berberine, like bifidobacterium and fluoxetine, significantly increases rat body weight following chronic stress modeling. The body weight of rats increased following modeling using the 10 unpredicted stress methods in all experimental groups. Prior to modeling, all drug intervention groups (low berberine, high berberine, bifidobacterium and fluoxetine) exhibited no significant differences in weight compared with each other. However, the mean weight of the model group decreased significantly following modeling $(323.39 \pm 19.6040 \mathrm{~g})$, when compared with the normal group $(440.91 \pm 13.1597 \mathrm{~g})$. Following modeling, the berberine (low berberine, $385.11 \pm 23.8284 \mathrm{~g}$; high berberine, $395.67 \pm 18.2214 \mathrm{~g}$ ) groups increased their mean body weight more than that observed in the model group $(323.39 \pm 19.6040 \mathrm{~g})$. Both bifidocaterium $(385.75 \pm 21.1776 \mathrm{~g})$ and fluoxetine $(389.43 \pm 25.5993 \mathrm{~g}$; Table I) groups demonstrated an identical pattern of results as the berberine groups.

Berberine significantly increases the traversing time, vertical movement and grooming times, as did bifidobacterium and fluoxetine, following chronic stress modeling. In an open field test, the traversing times of rats significantly decreased in the model group $(54.10 \pm 10.7647 \mathrm{sec})$ when

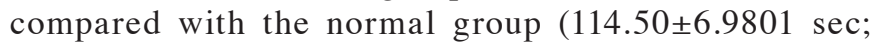
${ }^{* *} \mathrm{P}<0.01$; Table II). Traversing time in the low berberine group $(53.80 \pm 11.3117 \mathrm{sec})$ was not significantly different when compared with the model group (54.10 $\pm 10.7647 \mathrm{sec})$; 
however, the high berberine group $(84.30 \pm 11.5089 \mathrm{sec})$ was significantly increased when compared with the model group (54.10 $\pm 10.7647 \mathrm{sec} ;{ }^{* *} \mathrm{P}<0.01$; Table II). Bifidobacterium $(69.10 \pm 10.4823 \mathrm{sec})$ slightly increased traversing time when compared with the model group, and fluoxetine $(90.40 \pm 9.0086 \mathrm{sec})$ increased traversing time the most of the four drug groups. Similarly, vertical movement of rats significantly decreased in the model group $(7.50 \pm 1.4337 \mathrm{sec})$ compared with that of the normal group $(22.20 \pm 4.0222 \mathrm{sec}$; ${ }^{* *} \mathrm{P}<0.01$; Table II). The vertical movement time of rats in the low berberine group $(9.30 \pm 1.8886 \mathrm{sec})$ demonstrated no significant difference in time when compared with the model group $(7.50 \pm 1.4337 \mathrm{sec})$. However, the high berberine group was notably increased when comparing to the model group (7.50 $\pm 1.4337 \mathrm{sec}$; ${ }^{* *} \mathrm{P}<0.01$; Table II) Bifidobacterium $(12.80 \pm 3.2249 \mathrm{sec})$ and fluoxetine $(14.70 \pm 2.4060 \mathrm{sec})$ groups demonstrated similarly increased vertical movement times compared with the model group. In addition, rat grooming times significantly decreased in the model group $(0.70 \pm 0.4830 \mathrm{sec})$ when compared with the normal group $\left(3.70 \pm 0.8233 \mathrm{sec} ;{ }^{* *} \mathrm{P}<0.01\right.$; Table II). Rat grooming times in all drug groups were markedly increased when compared with the model group (low berberine, $1.80 \pm 0.7888 \mathrm{sec}$; high berberine, $2.70 \pm 0.6749 \mathrm{sec}$; bifidobacterium, $2.60 \pm 0.6992 \mathrm{sec}$; fluoxetine, $3.10 \pm 0.5676 \mathrm{sec}$; all ${ }^{* *} \mathrm{P}<0.01$; Table II). As expected, behavioral tests indicated chronic stress induced depression in the rats.

Chronic stress modeling significantly increases motionless time, and berberine, bifidobacterium and fluoxetine significantly decreases motionless time. The motionless time of rats in the model $(76.60 \pm 11.1176 \mathrm{sec})$ was significantly increased when compared with the rats in the normal group $\left(8.40 \pm 2.8363 \mathrm{sec},{ }^{* *} \mathrm{P}<0.01\right.$; Table III). Low berberine $(41.20 \pm 5.3083 \mathrm{sec})$ and high berberine $(22.60 \pm 4.1952 \mathrm{sec})$ were significantly decreased when compared with the model group $\left(76.60 \pm 11.1176 \mathrm{sec},{ }^{* *} \mathrm{P}<0.01\right.$; Table III) as that of bifidobacterium $(25.60 \pm 4.5265 \mathrm{sec})$ and fluoxetine $(17.80 \pm 3.2592 \mathrm{sec})$ positive control.

Sucrose preference decreases in the model group, and berberine significantly increases as with bifidobacterium and fluoxetine. In the sucrose preference test, rats sucrose preference significantly decreased in the model group $(55.10 \pm 10.03 \%)$ when compared with the normal group $\left(93.14 \pm 4.84 \% ;{ }^{* *} \mathrm{P}<0.01\right.$; Table IV). Low berberine $(76.72 \pm 5.52 \%)$, high berberine (78.95 $\pm 1.92 \%)$, bifidobacterium $(76.79 \pm 1.90 \%)$ and fluoxetine $(87.16 \pm 3.85 \%)$ groups demonstrated an increased sucrose preference when compared with the model group $(55.10 \pm 10.03 \%$; ${ }^{* *} \mathrm{P}<0.01$; Table IV).

Histopathological analysis of rat gastrointestinal contents demonstrates severe damage following modeling, which was reversed by berberine, bifidobacterium and fluoxetine. Histopathological assays demonstrated that the model group exhibited severe damage to the gastric mucosa and intestinal microvilli, as well as exhibiting a looser cell structure, mild nuclear contraction, deep staining, and inflammatory cell invasion in the stomach, ileum, cecum and colon tissues. Following low and high berberine treatment, the rat gastric
Table III. Measurements of motionless time during a forced-swimming test following modeling.

\begin{tabular}{lc}
\hline Group & $\begin{array}{c}\text { Motionless time during } \\
\text { forced-swimming }(\mathrm{sec} ; \mathrm{n}=10)\end{array}$ \\
\hline Normal & $8.40 \pm 2.8363$ \\
Model & $76.60 \pm 11.1176^{\mathrm{b}}$ \\
Low berberine & $41.20 \pm 5.3083^{\mathrm{b}}$ \\
High berberine & $22.60 \pm 4.1952^{\mathrm{b}}$ \\
Bifidobacterium & $25.60 \pm 4.5265^{\mathrm{b}}$ \\
Fluoxetine & $17.80 \pm 3.2592^{\mathrm{b}}$ \\
\hline
\end{tabular}

Data are presented as the mean $\pm \mathrm{SD}\left({ }^{\mathrm{a}} \mathrm{P}<0.05,{ }^{\mathrm{b}} \mathrm{P}<0.01 \mathrm{vs}\right.$. the normal group).

Table IV. Sucrose preference assay post-modeling.

\begin{tabular}{lc}
\hline Group & $\begin{array}{c}\text { Sucrose preference } \\
(\mathrm{n}=10)(\%)\end{array}$ \\
\hline Normal & $93.14 \pm 4.84$ \\
Model & $55.10 \pm 10.03^{\mathrm{b}}$ \\
Low berberine & $76.72 \pm 5.52^{\mathrm{b}}$ \\
High berberine & $78.95 \pm 1.92^{\mathrm{b}}$ \\
Bifidobacterium & $76.79 \pm 1.90^{\mathrm{b}}$ \\
Fluoxetine & $87.16 \pm 3.85^{\mathrm{b}}$ \\
\hline
\end{tabular}

Data are presented as the mean \pm standard deviation $\left({ }^{\mathrm{a}} \mathrm{P}<0.05,{ }^{\mathrm{b}} \mathrm{P}<0.01\right.$ vs. the normal group).

mucosa and intestinal microvilli, and cells structure gradually returned to normal, presenting no inflammatory cell invasion in stomach, ileum, cecum and colon tissues, unlike following treatment with either bifidobacterium or the fluoxetine positive control (Figs. 1-4).

ERIC-PCR analysis comparing drug intervention groups with the model and normal groups. ERIC-PCR was used to perform a gastrointestinal flora profile assay on the rat stomach, ileum, cecum and colon tissues. Following modeling, several distinctive bands disappeared when compared with the normal group. In addition, certain new distinctive bands appeared in the low and high berberine groups, similar to the results of the bifidobacterium and fluoxetine treatment groups. For example, two new bands appeared in the stomach tissue following modeling at 2,000 bp and between 750 bp and 500 bp in lanes 4-6 of the model group results. Several distinctive bands appeared following treatment with low and high berberine, including a new band between 750-500 bp in lanes 1-4 following low berberine treatment, and in lanes 1-3 following high berberine treatment (Fig. 5). Similarly, several distinctive bands appeared and disappeared in the other tissues analyzed, within the ileum (Fig. 6), cecum (Fig. 7) and colon (Fig. 8). These data indicate that berberine altered the gastrointestinal flora, and may be further affected by depression. 
Normal

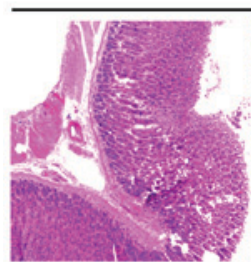

$(40 \times)$

$(40 \times)$

$(100 \times)$

$(100 \times)$
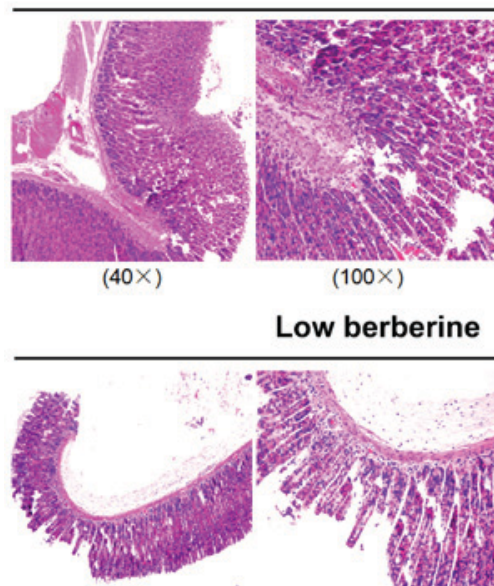

Low berberine

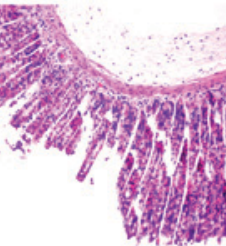

Bifidobacterium

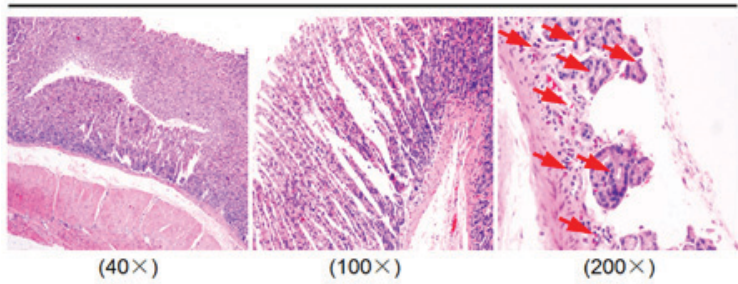

$(100 \times)$

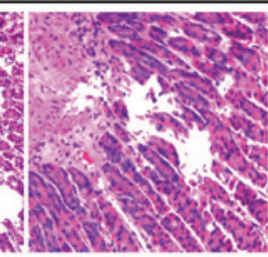

$(200 \times)$

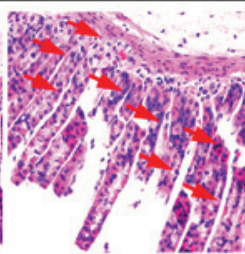

$(200 \times)$

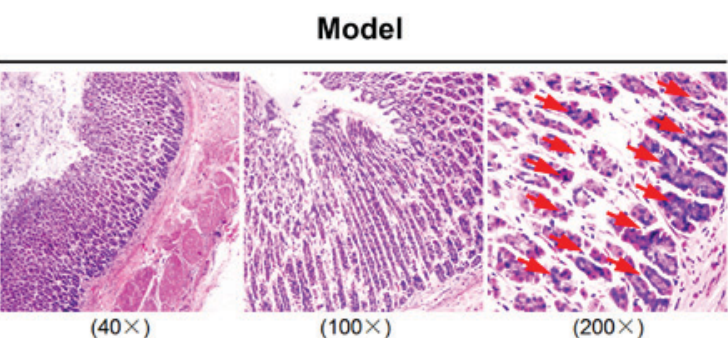

High berberine

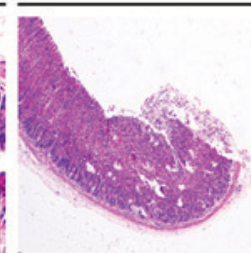

$(40 \times)$

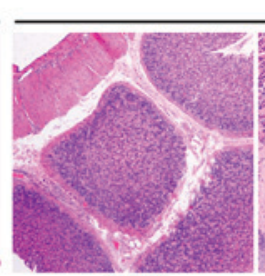

$(40 \times)$

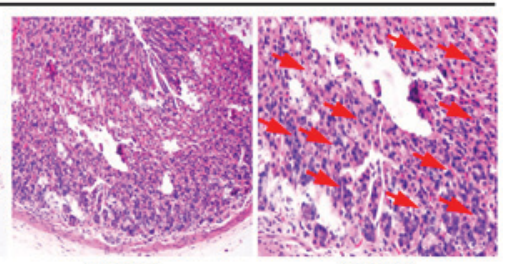

$(100 \times)$

Fluoxetine

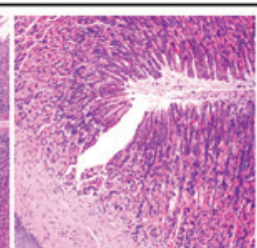

$(100 \times)$

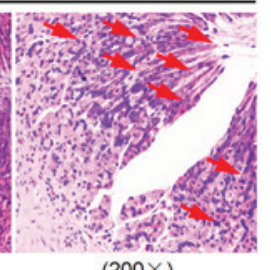

(200X)

Figure 1. Histopathology assay of a rat stomach using hematoxylin and eosin staining. Damage to rat gastric mucosa, intestinal microvilli, inflammatory cell invasion and cell structure became gradually restored to normal in the stomach following low and high berberine treatment, similar to the effects of bifidobacterium and fluoxetine, when compared with the model group (magnification, x40, x100 and x200).

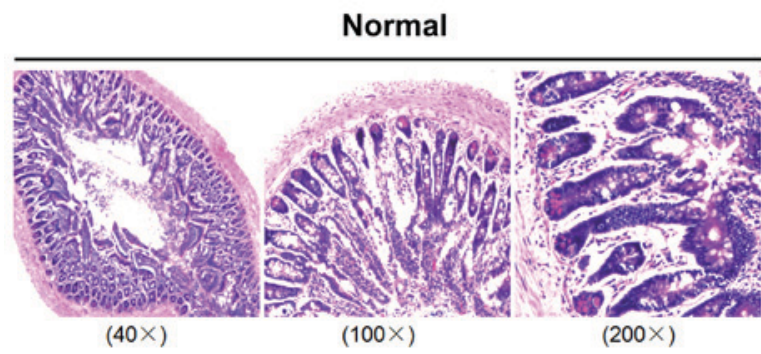

Low berberine

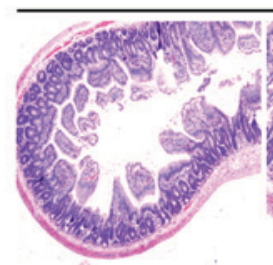

$(40 \times)$

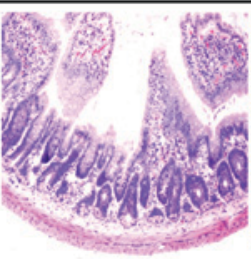

$(100 \times)$

Bifidobacterium

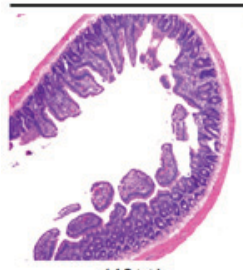

(40X)

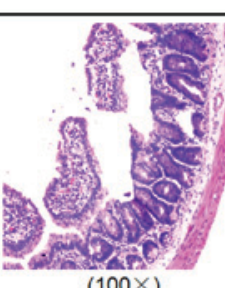

$(100 \times)$

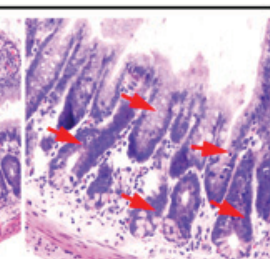

$(200 \times)$

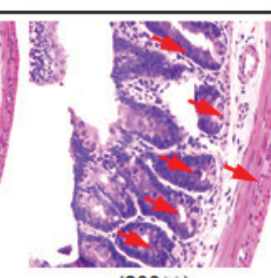

$(200 \times)$

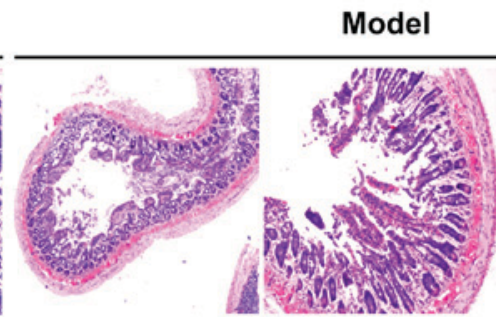

$(100 \times)$

(40X)

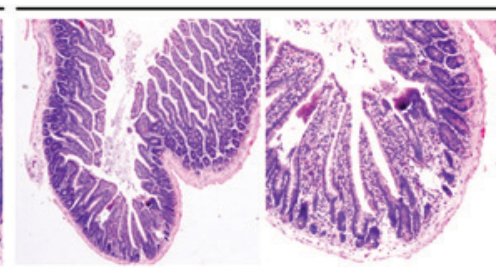

$(40 \times)$

$(100 \times)$

Fluoxetine

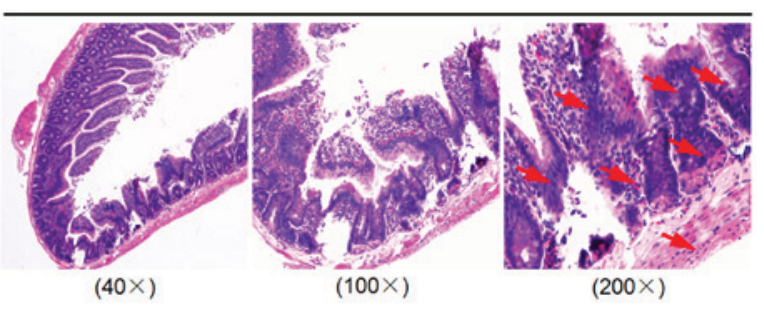

Figure 2. Histopathology assay of a rat ileum using hematoxylin and eosin staining. Damage to rat gastric mucosa, intestinal microvilli, inflammatory cell invasion and cell structure became gradually restored to normal in the ileum following low and high berberine treatment, similar to the effects of bifidobacterium and fluoxetine, when compared with the model group (magnification, x40, x100 and x200). 
Normal

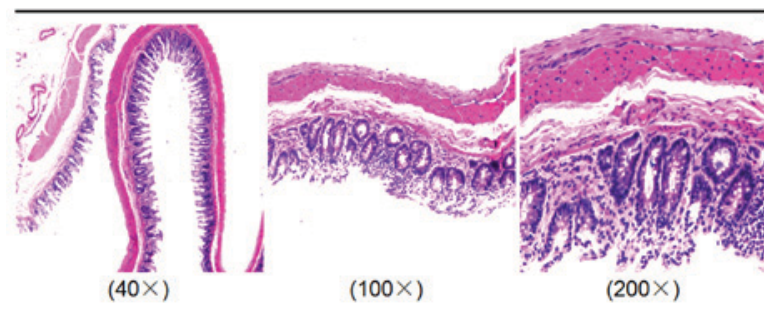

Low berberine

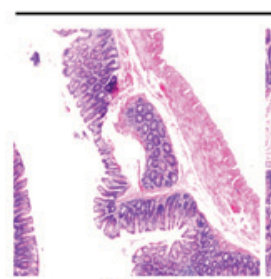

$(40 \times)$

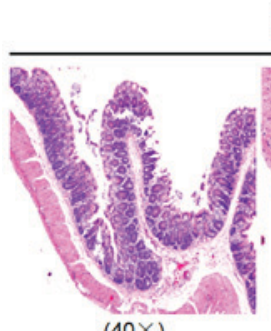

$(40 \times)$

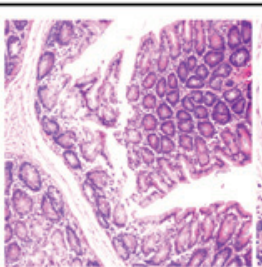

$(100 \times)$

Bifidobacterium

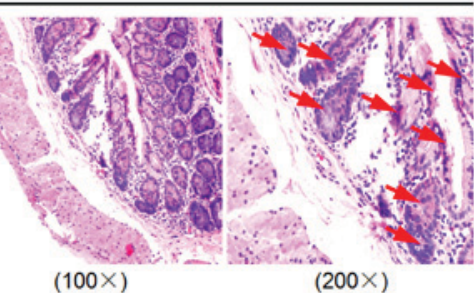

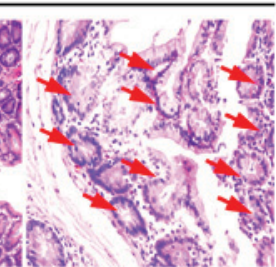

$(200 \times)$

$(200 \times)$

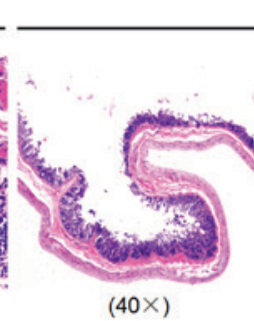

$(40 \times)$
Model

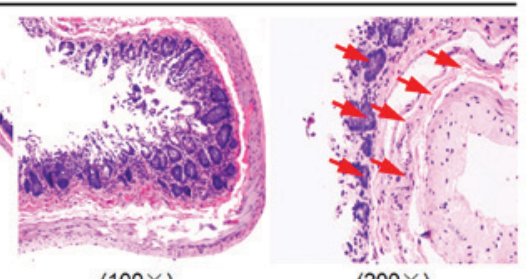

$(100 \times)$

High berberine

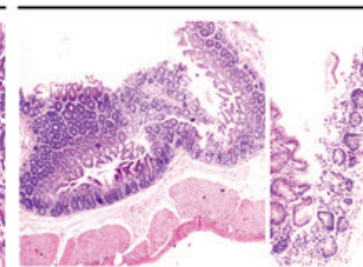

$(40 \times)$

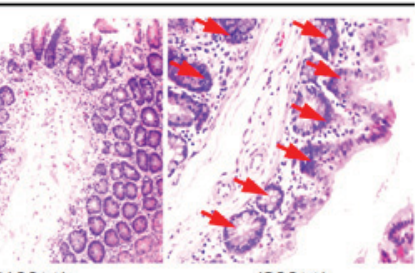

$(200 \times)$

\section{Fluoxetine}

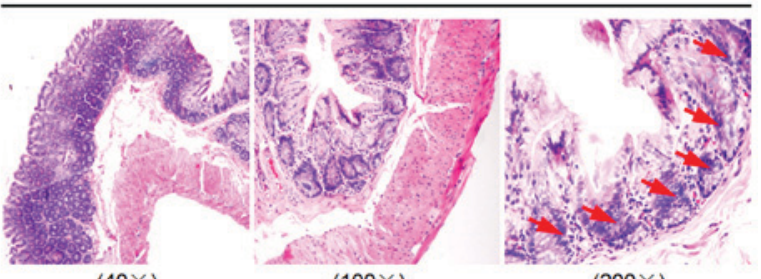

$(40 \times)$

$(100 \times)$

$(200 \times)$

Figure 3. Histopathology assay of a rat cecum using hematoxylin and eosin staining. Damage to rat gastric mucosa, intestinal microvilli, inflammatory cell invasion and cell structure became gradually restored to normal in the cecum following low and high berberine treatment, similar to the effects of bifidobacterium and fluoxetine, when compared with the model group (magnification, $\mathrm{x} 40$, x100 and x200).
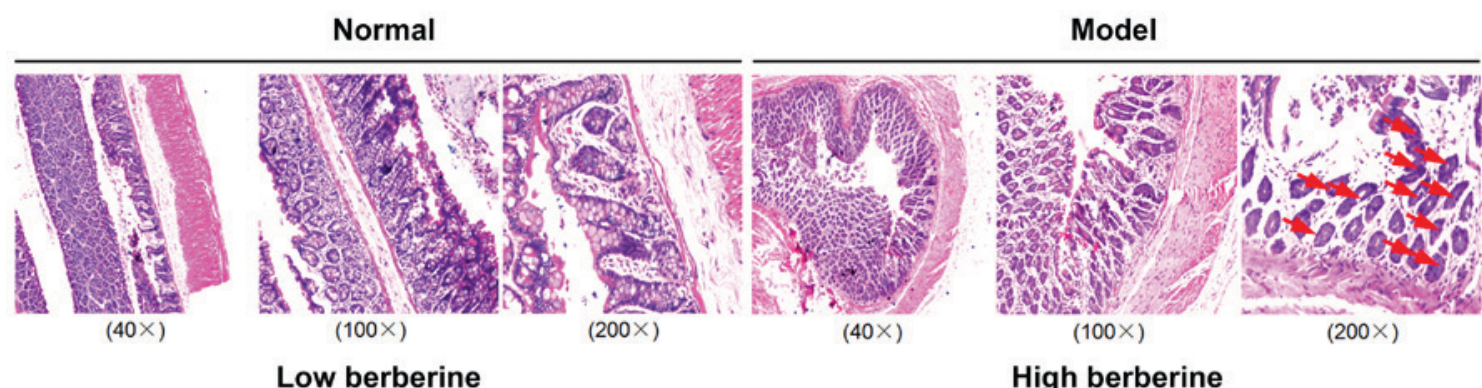

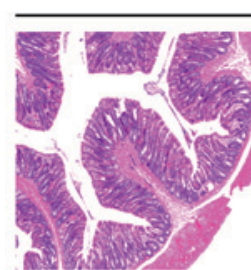

$(40 \times)$

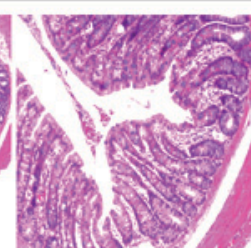

$(100 \times)$

Bifidobacterium
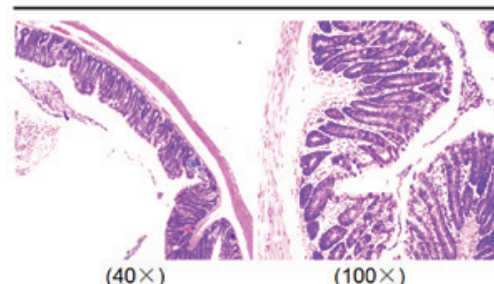
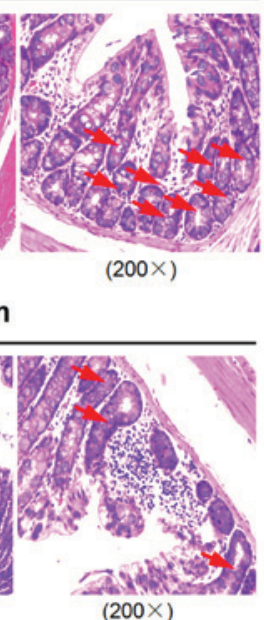

$(200 \times)$

$(200 \times)$
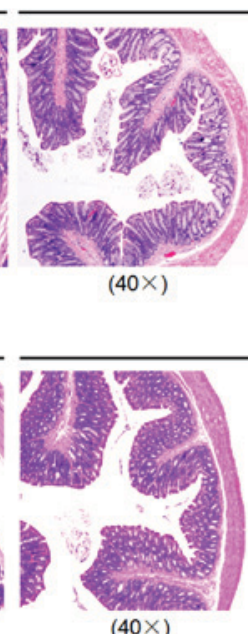

High berberine

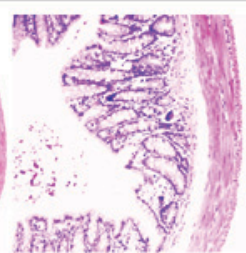

$(100 \times)$

Fluoxetine

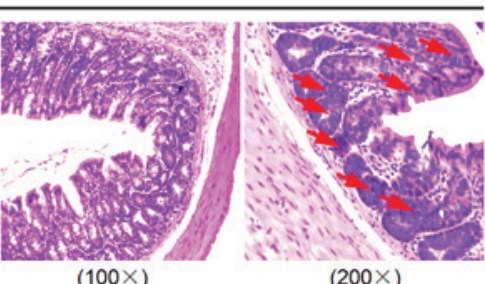

Figure 4. Histopathology assay of a rat colon using hematoxylin and eosin staining. Damage to rat gastric mucosa, intestinal microvilli, inflammatory cell invasion and cell structure became gradually restored to normal in the colon following low and high berberine treatment, similar to the effects of bifidobacterium and fluoxetine, when compared with the model group (magnification, x40, x100 and x200). 


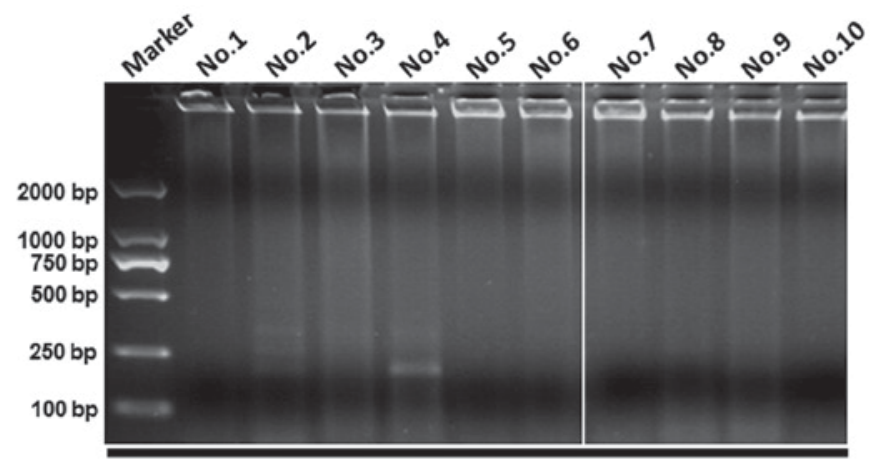

Normal

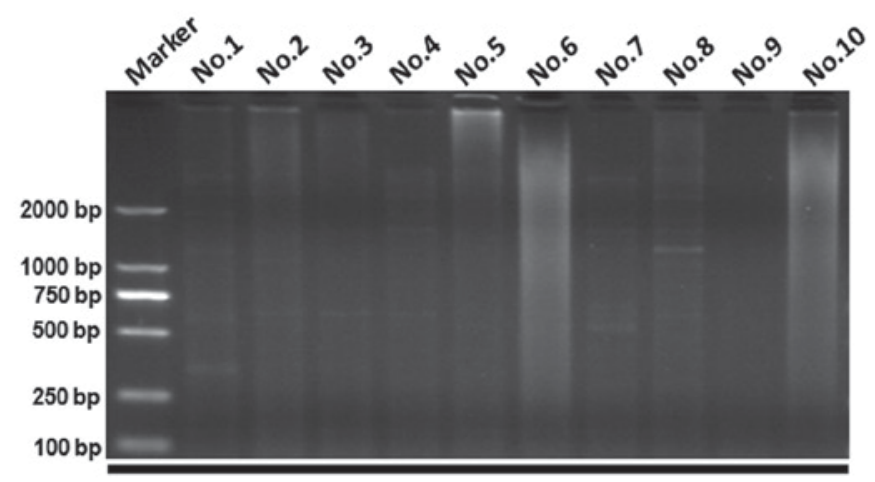

Low berberine

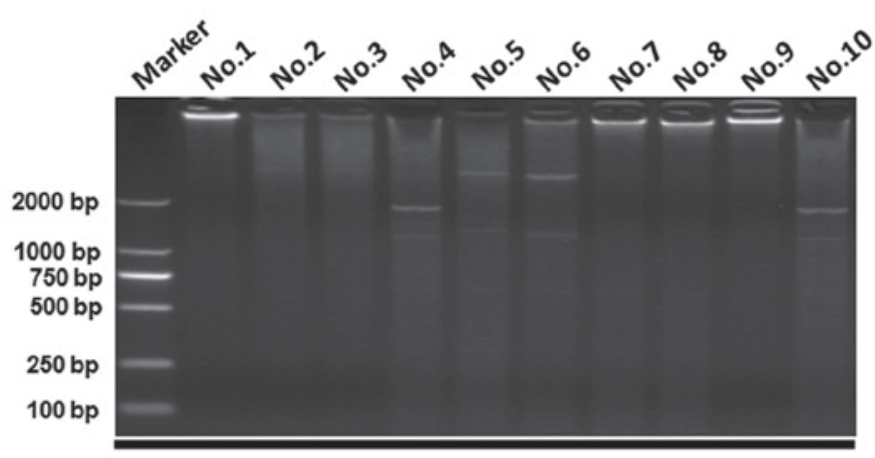

Bifidobacterium

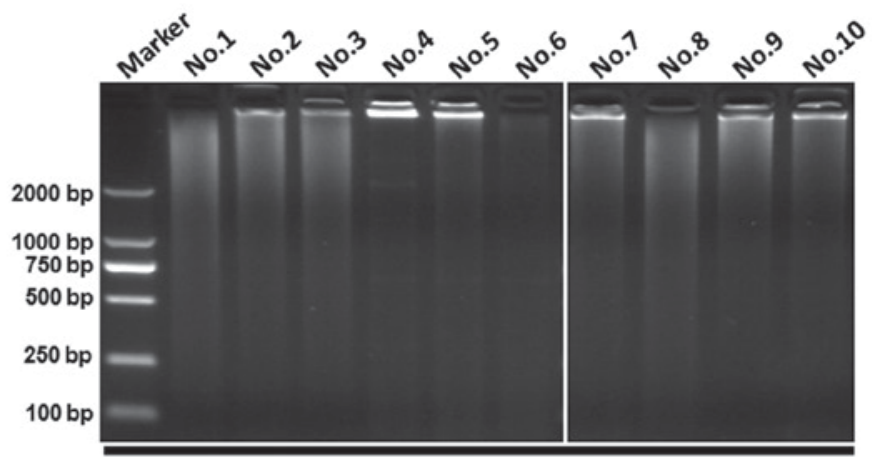

Model

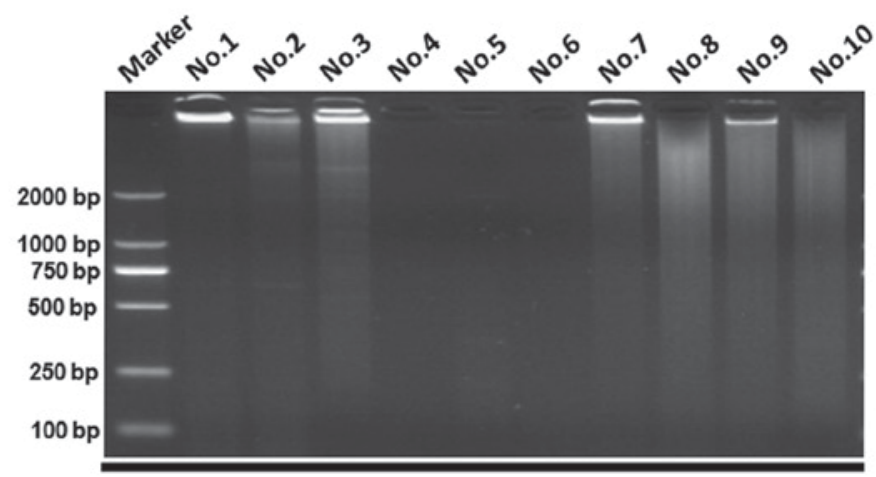

High berberine

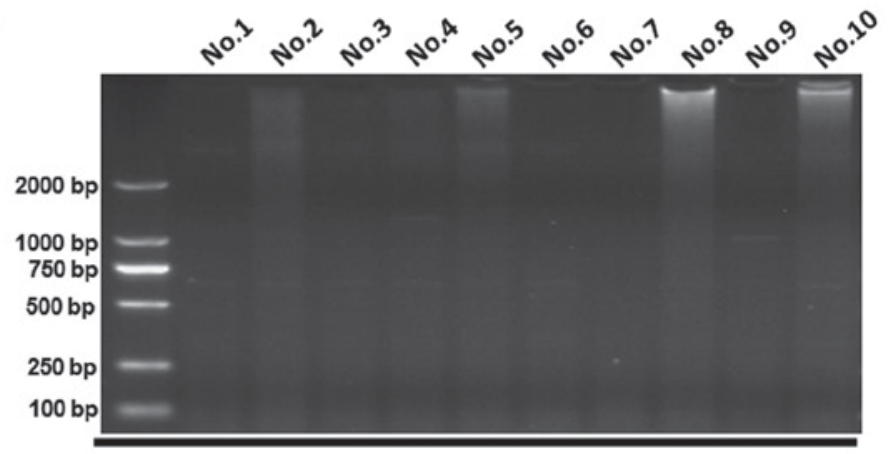

Fluoxetine

Figure 5. Gastrointestinal flora profile assay of a rat stomach using enterobacterial repetitive intergenic consensus sequence-based polymerase chain reaction. Several new distinctive bands appeared in the stomach assay following low and high berberine treatment, similar to that of bifidobacterium and fluoxetine, when compared with the model group. Lanes refer to the identification of the rats.

\section{Discussion}

Following undergoing 10 stress methods, rat body weight and sucrose preference significantly decreased when compared with unstressed rats. This was gradually restored following graded berberine treatment. In addition, the traversing, grooming and motionless times were all increased following modeling and decreased again following graded berberine treatment. Furthermore, berberine appeared beneficial in the restoration of pathological damage to rat stomach, ileum, cecum and colon, as demonstrated using ERIC-PCR analysis.

Gastrointestinal flora is a normal microbial population that is widely distributed in living organisms, involved in the synthesis of multiple nutrients, including vitamins, proteins and metals (28-30). A total of 10 trillion bacteria exist within the human gastrointestinal system and may be divided into three groups: Beneficial, neutral and pernicious bacteria, according to their differing functions. These functions are not only influenced by body weight, digestive ability, outstanding infection and the risk of autoimmune disease, but are also involved in the body's response to cancer therapeutic agents $(28,31,32)$. Following a disturbance to the gastrointestinal flora, diseases may emerge (33). Gastrointestinal flora may be divided into major and minor microflora. Major microflora consist of obligate anaerobes with a large number of involved species, including bacteroides, eubacterium, bifidobacterium, ruminococci and fusobacterium, all of which influence the function of host flora and determine physiological and 


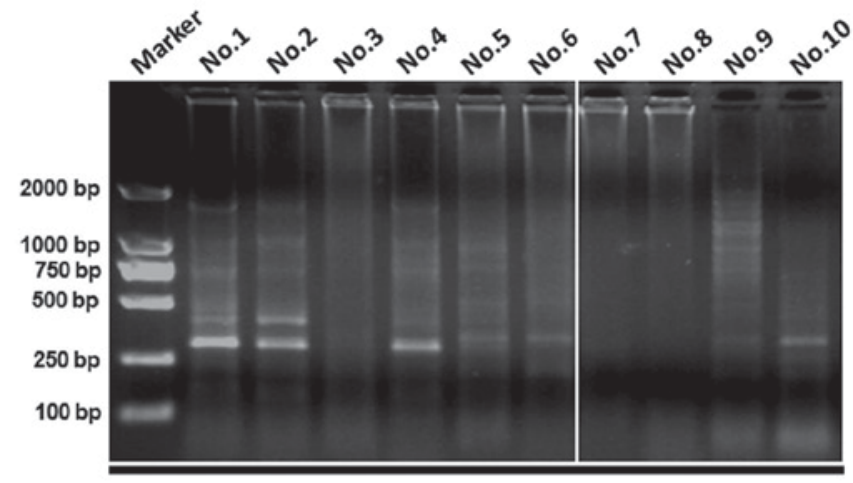

Normal

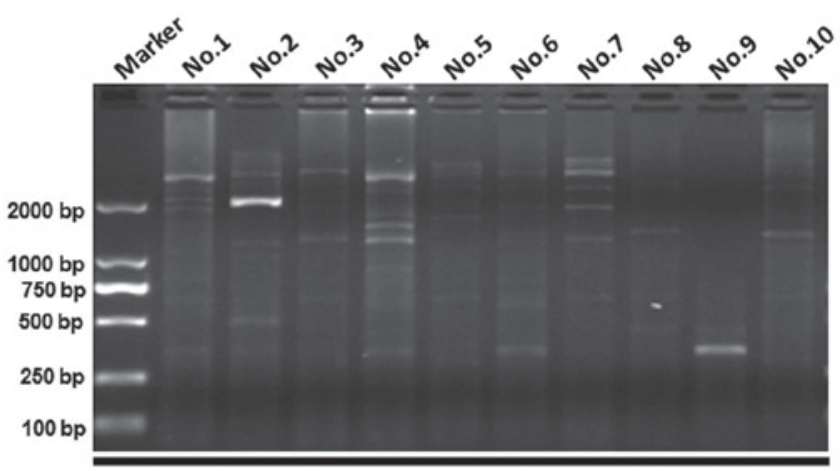

Low berberine

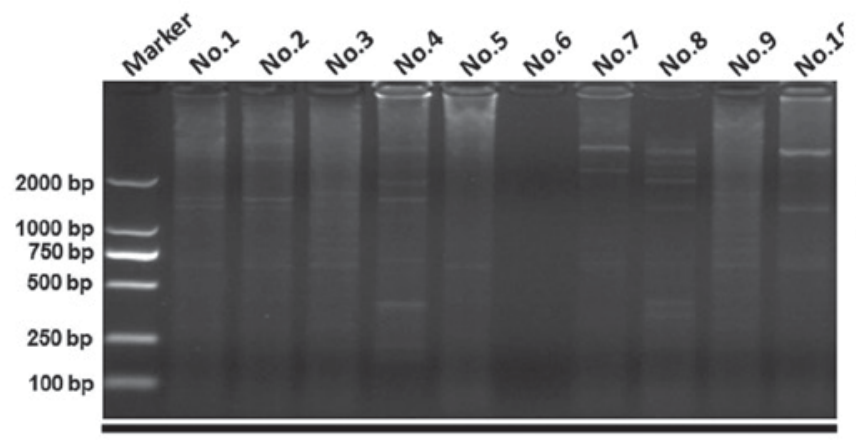

Bifidobacterium

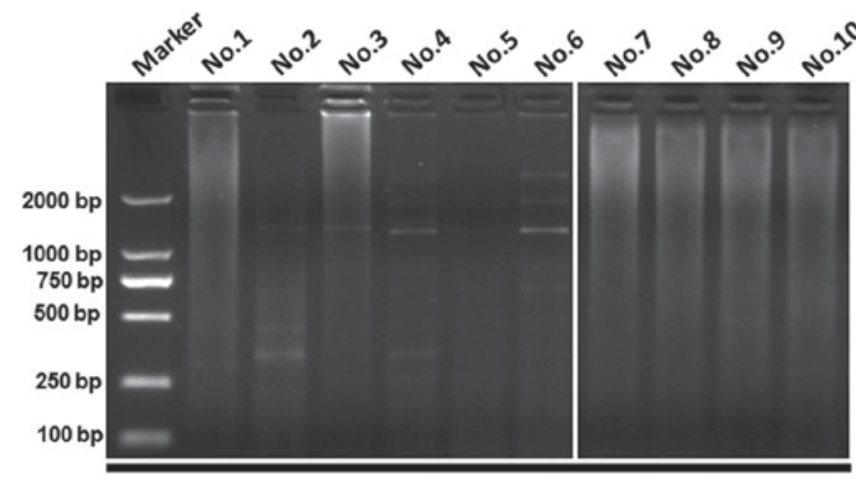

Model

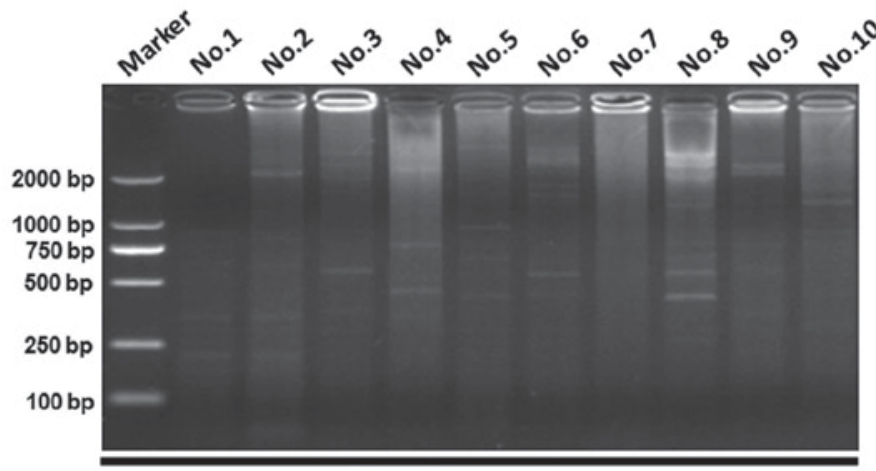

High berberine

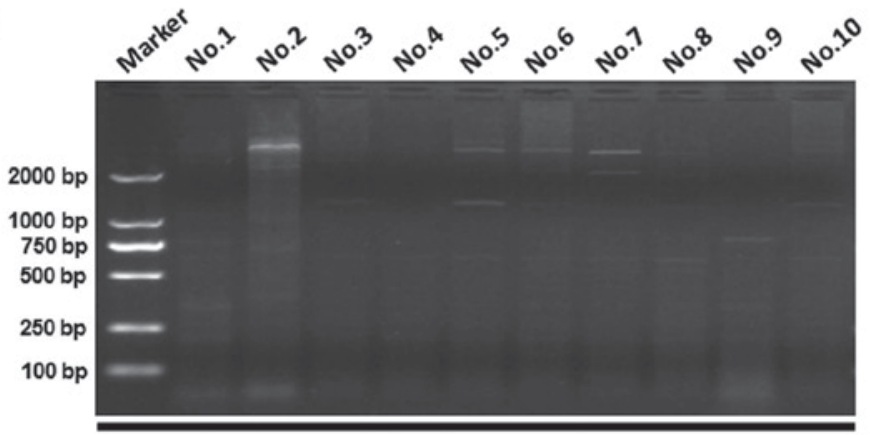

Fluoxetine

Figure 6. Gastrointestinal flora profile assay of a rat ileum using enterobacterial repetitive intergenic consensus sequence-based polymerase chain reaction. Several new distinctive bands appeared in the ileum following low berberine and high berberine treatment, similar to that of bifidobacterium and fluoxetine, when compared with the model group. Lanes refer to the identification of the rats.

pathological regulation $(28,29)$. Minor microflora consist of facultative anaerobes, fewer in number and species, including Escherichia coli and streptococcus, which have high mobility and potential pathogenicity $(28,34)$. Major microflora typically exist in a microhabitat with low disposal rate and highly abundant nutrients, for example, the colon $(28,32,34)$. Aerobe or facultative anaerobe typically exist in microhabitats with a higher disposal rate, for example, the proximal small intestine (35). As gastrointestinal flora and depression have previously been linked, studying the major microflora in different orifices, particularly the change of major microflora after stress stimulation, was beneficial to prevention and treatment of these diseases.

ERIC sequences were initially discovered and named by Sharples and Lloyd (36) and described in a number of other previous studies (37-39). Following this, Hulton et al (40) discovered ERIC sequences in the genome of Escherichia coli and the genus Salmonella, and Versalovic et al (41) designed a PCR primer using the sequence of ERIC, and established a ERIC-PCR amplification technique in the same year. This technique involves designing a PCR primer according to the highly conserved sequence of the ERIC core, subsequent amplification, followed by analysis of the ERIC-PCR profile to identify the major microflora distribution in gastrointestinal flora (41). In the present study, the ERIC-PCR technique was selected and used to identify the variation of gastrointestinal flora in a rat model, following ten stress methods and/or drug intervention. Although several distinctive bands appeared with or without drug intervention, this method requires further analysis. 


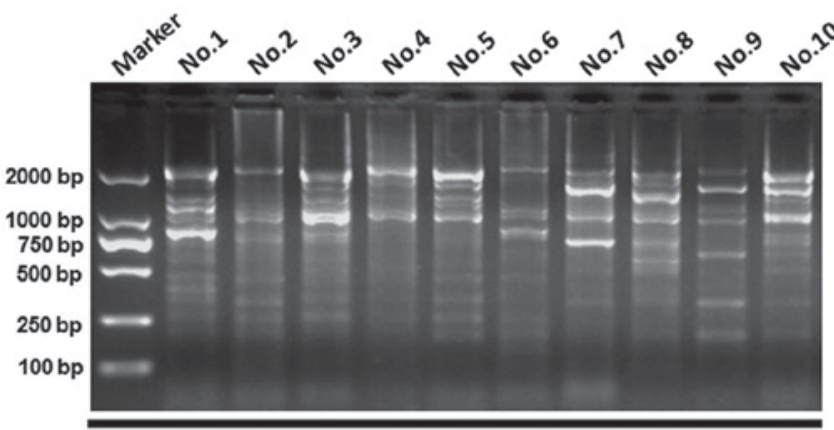

Normal

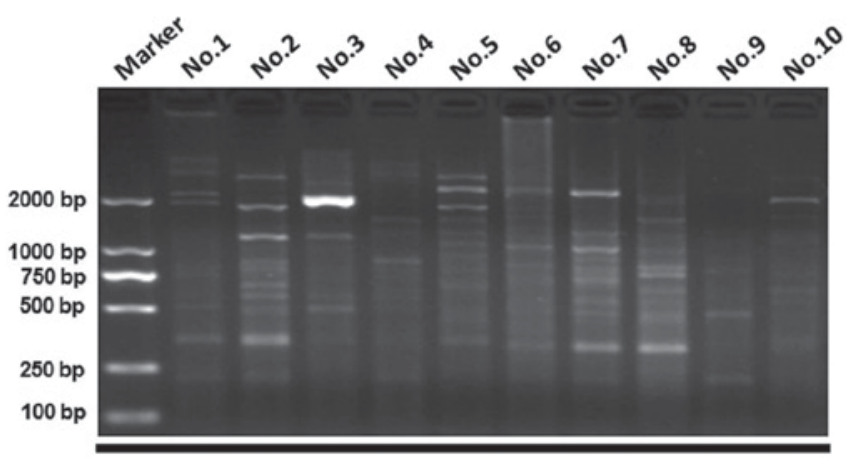

Low berberine

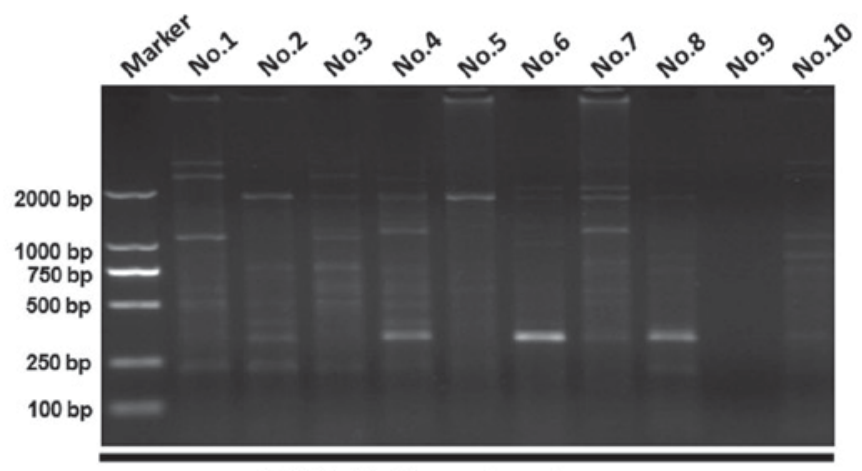

Bifidobacterium

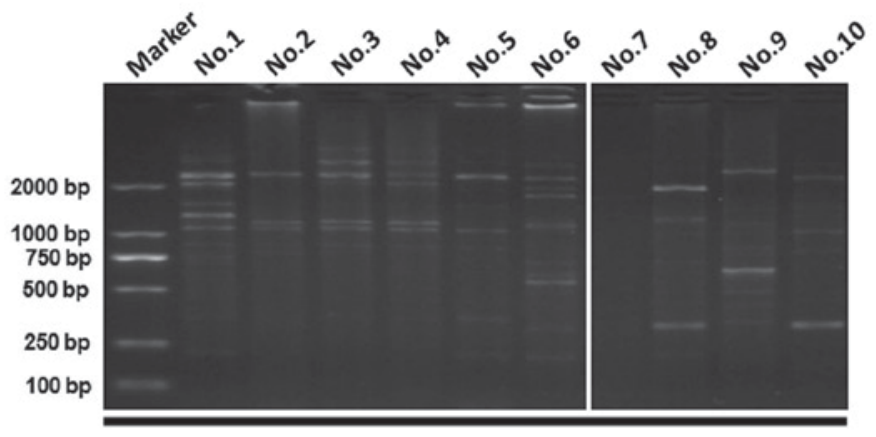

Model

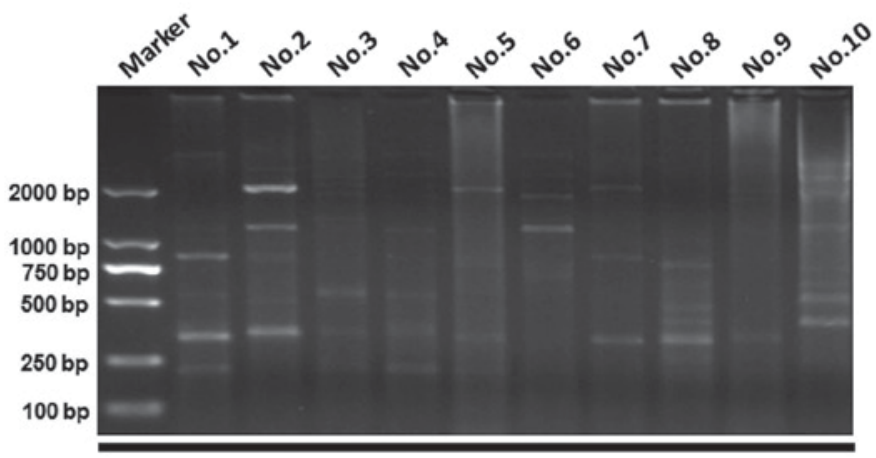

High berberine

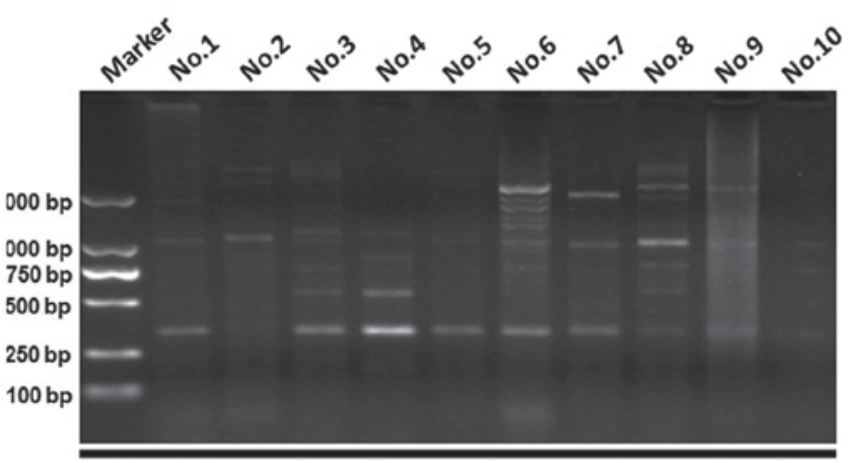

Fluoxetine

Figure 7. Gastrointestinal flora profile assay of a rat cecum using enterobacterial repetitive intergenic consensus sequence-based polymerase chain reaction. Several new distinctive bands appeared in the cecum following low and high berberine treatment similar to that of bifidobacterium and fluoxetine, when compared with the model group. Lanes refer to the identification of the rats.

Berberine is a quaternary ammonium salt from the protoberberine group of isoquinoline alkaloids, and it is present in certain plants, including Berberis vulgaris and Hydrastis canadensis (42). Berberine was traditionally used as a medicine or dietary supplement against fungal (43) and MRSA infections (44). Previous studies identified certain novel functions of berberine, including prevention of cardiovascular disease (45), anti-inflammatory effects (45), treatment of diabetes mellitus (46), antidepressant effects (47-49) and neuroprotection (50). Therefore, the present study aimed to further investigate the effects of the antidepressant effects of berberine in a rat model of chronic stress and depression. Following berberine treatment after inducing stress, rat behavior, motionless time, sucrose preference, histopathology and gastrointestinal flora profile markedly improved. The results presented indicated that berberine may serve a significant therapeutic effect in the treatments of chronic stress and depression.

The present study induced chronic stress and depression according to the results of the behavioral tests using chronic unpredictable stress methods, and identified that treatment with berberine not only provided a significant reference point for studying the mechanism of chronic stress depression, but also demonstrated a significant application in a clinical setting.

\section{Acknowledgements}

The present study was supported by the Armed Police Force Scientific Research Fund Project (grant no. WZ2012050). 


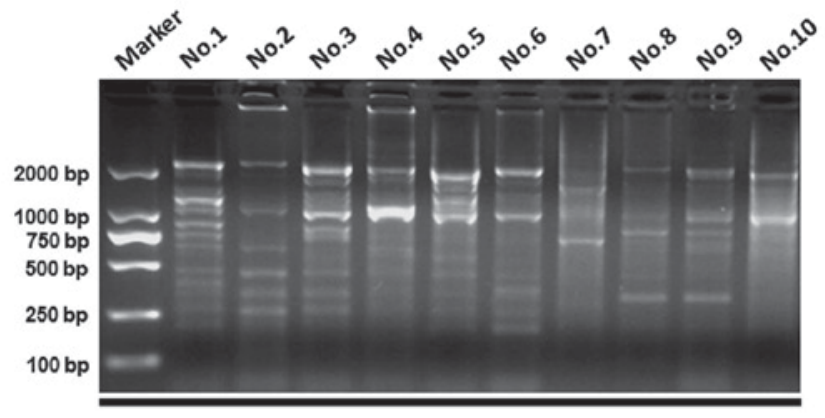

Normal

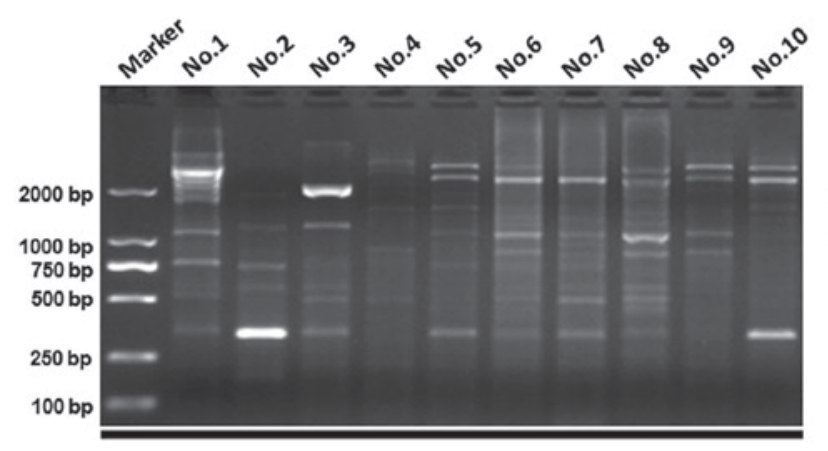

Low berberine

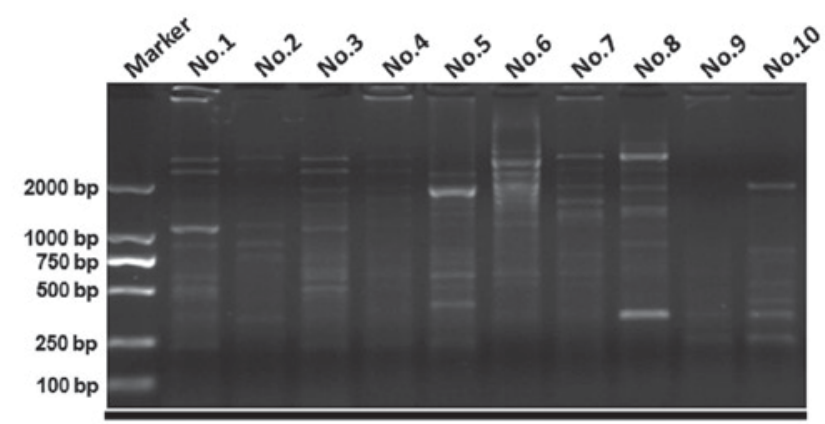

Bifidobacterium

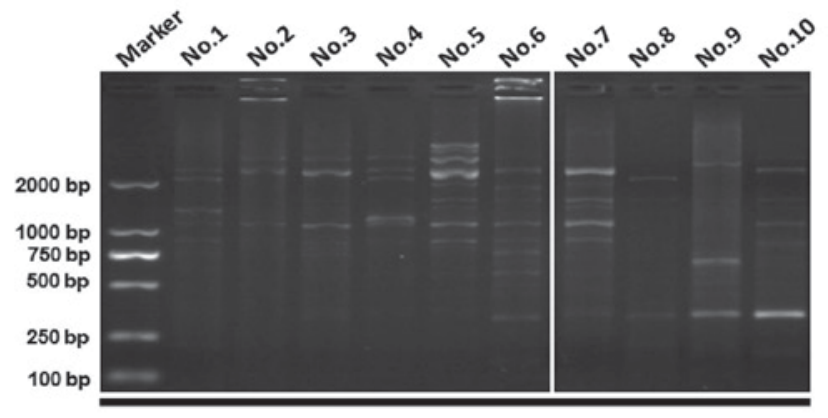

Model

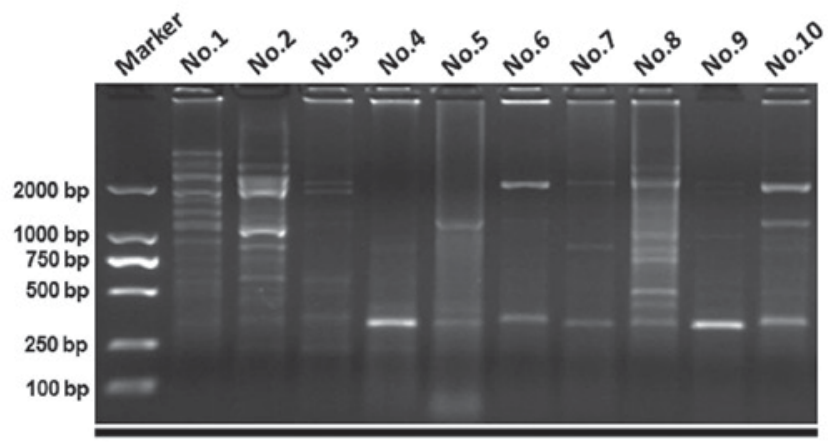

High berberine

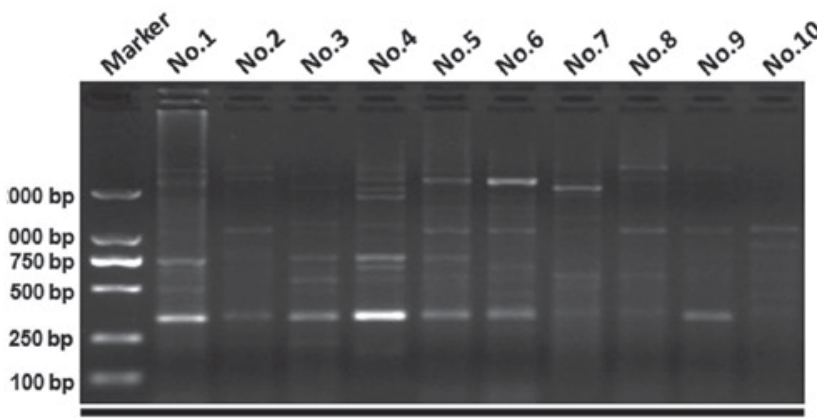

Fluoxetine

Figure 8. Gastrointestinal flora profile assay of a rat colon using enterobacterial repetitive intergenic consensus sequence-based polymerase chain reaction. Several new distinctive bands appeared in the colon following low and high berberine treatment, similar to that of bifidobacterium and fluoxetine, when compared with the model group. Lanes refer to the identification of the rats.

\section{References}

1. Technow JR, Hazel NA, Abela JR and Hankin BL: Stress sensitivity interacts with depression history to predict depressive symptoms among youth: Prospective changes following first depression onset. J Abnorm Child Psychol 43: 489-501, 2015.

2. Mayberry LS, Egede LE, Wagner JA and Osborn CY: Stress, depression and medication nonadherence in diabetes: Test of the exacerbating and buffering effects of family support. J Behav Med 38: 363-371, 2015.

3. Fan LB, Blumenthal JA, Watkins LL and Sherwood A: Work and home stress: Associations with anxiety and depression symptoms. Occup Med (Lond) 65: 110-116, 2015.

4. Wang X, Cai L, Qian J and Peng J: Social support moderates stress effects on depression. Int J Ment Health Syst 8: 41, 2014

5. Reynaud E, Guedj E, Trousselard M, El Khoury-Malhame M, Zendjidjian X, Fakra E, Souville M, Nazarian B, Blin O, Canini $\mathrm{F}$ and Khalfa $\mathrm{S}$ : Acute stress disorder modifies cerebral activity of amygdala and prefrontal cortex. Cogn Neurosci 6: $39-43,2015$
6. Pulopulos MM, Hidalgo V, Almela M, Puig-Perez S, Villada C and Salvador A: Acute stress and working memory in older people. Stress 18: 178-187, 2015.

7. Nilsson D, Nordenstam C, Green S, Wetterhall A, Lundin T and Svedin CG: Acute stress among adolescents and female rape victims measured by ASC-Kids: A pilot study. Nord J Psychiatry 69: 539-545, 2015.

8. Gonzalez M, Melamed G and Dillon C: Acute stress disorder in the emergency, its relationship with trigger factors from a gender perspective. Vertex 25: 172-178, 2014 (In Spanish).

9. Razzoli M, McCallum J, Gurney A, Engeland WC and Bartolomucci A: Chronic stress aggravates glucose intolerance in leptin receptor-deficient (db/db) mice. Genes Nutr 10: 458, 2015.

10. Radenbach C, Reiter AM, Engert V, Sjoerds Z, Villringer A, Heinze HJ, Deserno L and Schlagenhauf F: The interaction of acute and chronic stress impairs model-based behavioral control. Psychoneuroendocrinology 53: 268-280, 2015.

11. Hoffman AN, Parga A, Paode PR, Watterson LR, Nikulina EM, Hammer RP Jr and Conrad CD: Chronic stress enhanced fear memories are associated with increased amygdala zif268 mRNA expression and are resistant to reconsolidation. Neurobiol Learn Mem 120: 61-68, 2015. 
12. Breuer K, Göldner FM, Jager B, Werfel T and Schmid-Ott G: Chronic stress experience and burnout syndrome have appreciable influence on health-related quality of life in patients with psoriasis. J Eur Acad Dermatol Venereol 29: 1898-1904, 2015.

13. Gutknecht L, Popp S, Waider J, Sommerlandt FM, Göppner C, Post A, Reif A, van den Hove D, Strekalova T, Schmitt A, et al: Interaction of brain 5-HT synthesis deficiency, chronic stress and sex differentially impact emotional behavior in Tph2 knockout mice. Psychopharmacology (Berl) 232: 2429-2441, 2015.

14. Elfving B, Jakobsen JL, Madsen JC, Wegener G and Muller HK: Chronic restraint stress increases the protein expression of VEGF and its receptor VEGFR-2 in the prefrontal cortex. Synapse 190-194: 69, 2015.

15. Duncan J, Wang N, Zhang X, Johnson S, Harris S, Zheng B, Zhang Q, Rajkowska G, Miguel-Hidalgo JJ, Sittman D, et al: Chronic social stress and ethanol increase expression of KLF11, a cell death mediator, in rat brain. Neurotox Res 28: 18-31, 2015.

16. Zhao J, Jung YH, Jang CG, Chun KH, Kwon SW and Lee J: Metabolomic identification of biochemical changes induced by fluoxetine and imipramine in a chronic mild stress mouse mode of depression. Sci Rep 5: 8890, 2015.

17. Xing H, Zhang K, Zhang R, Zhang Y, Gu L, Shi H, Bi K and Chen X: Determination of depression biomarkers in rat plasma by liquid chromatography-mass spectrometry for the study of the antidepressant effect of $\mathrm{Zhi}-\mathrm{Zi}-\mathrm{Hou}-\mathrm{Po}$ decoction on rat model of chronic unpredictable mild stress. J Chromatogr B Analyt Technol Biomed Life Sci 988: 135-142, 2015.

18. Thompson AK, Fourman S, Packard AE, Egan AE, Ryan KK and Ulrich-Lai YM: Metabolic consequences of chronic intermittent mild stress exposure. Physiol Behav 150: 24-30, 2015.

19. $\mathrm{Yu} \mathrm{M}$, Zhang $\mathrm{X}, \mathrm{Lu} \mathrm{F}$ and Fang L: Depression and risk for diabetes: A meta-analysis. Can J Diabetes 39: 266-272, 2015

20. Smith HR: Depression in cancer patients: Pathogenesis, implications and treatment (Review). Oncol Lett 9: 1509-1514, 2015.

21. Fagelman KM, Methratta S, Cilley RE, Wilson MZ and Hollenbeak CS: The depression index: An objective measure of the severity of pectus excavatum based on vertebral diameter, a morphometric correlate to patient size. J Pediatr Surg 50: $1130-1133,2015$

22. Tchuenbou J, Hamy A, Papapietro V, Sagan C, Paineau J and Le Bodic L: Gastrointestinal mucormycosis: A rare cause of digestive system hemorrhage. Gastroenterol Clin Biol 23: 794-795, 1999 (In French).

23. Infant nutrition: Metabolism and the digestive system Proceedings, international symposium in infant nutrition and the development of the gastrointestinal tract. Niagara falls, Ontario, June 21-25, 1982. J Pediatr Gastroenterol Nutr 2 (Suppl 1): S1-S342, 1983

24. Gastrointestinal hormones and pathology of the digestive system. Adv Exp Med Biol 106: 1-326, 1978.

25 . Results in gastroenterology 1978. Immune system and the gastrointestinal tract; classification and therapy of intestinal neoplasms 33rd meeting of the German society for digestive and metabolic diseases, Hamburg, 28-30 September 1978. Z Gastroenterol Verh: 1-115, 1978 (In German).

26. Cossel L: Functional disorders of the gastrointestinal system; a contribution to the chronic digestive disorders of the duodenum and to the acute stomach dilatation. Zentralbl Chir 80: 273-289, 1955 (In German).

27. Ge L, Zhu MM, Yang JY, Wang F, Zhang R, Zhang JH, Shen J, Tian HF and Wu CF: Differential proteomic analysis of the anti-depressive effects of oleamide in a rat chronic mild stress model of depression. Pharmacol Biochem Behav 131: 77-86, 2015.

28. Adak A, Maity C, Ghosh K and Mondal KC: Alteration of predominant gastrointestinal flora and oxidative damage of large intestine under simulated hypobaric hypoxia. Z Gastroenterol 52: 180-186, 2014
29. Wiwanitkit V: Antibiotic and gastrointestinal tract flora. Vet Microbiol 148: 452, 2011

30. Shimizu K, Ogura H, Asahara T, Nomoto K, Morotomi M, Nakahori Y, Osuka A, Yamano S, Goto M, Matsushima A, et al: Gastrointestinal dysmotility is associated with altered gut flora and septic mortality in patients with severe systemic inflammatory response syndrome: A preliminary study. Neurogastroenterol Motil 23: 330-335, e157, 2011

31. Björkstén B: Impact of gastrointestinal flora on systemic diseases. J Pediatr Gastroenterol Nutr 46 (Suppl 1): E12-E13, 2008.

32. Shanahan F: Gut flora in gastrointestinal disease. Eur J Surg Suppl: 47-52, 2002.

33. Marteau P: Role of the intestinal flora in gastrointestinal diseases. Lancet 356 (Suppl): s28, 2000

34. Adams JB, Johansen LJ, Powell LD, Quig D and Rubin RA: Gastrointestinal flora and gastrointestinal status in children with autism-comparisons to typical children and correlation with autism severity. BMC Gastroenterol 11: 22, 2011.

35. Huis in 't Veld JH: Gastrointestinal flora and health in man and animal. Tijdschr Diergeneeskd 116: 232-239, 1991 (In Dutch).

36. Sharples GJ and Lloyd RG: A novel repeated DNA sequence located in the intergenic regions of bacterial chromosomes. Nucleic Acids Res 18: 6503-6508, 1990.

37. Ture M, Altinok I and Capkin E: Comparison of pulsed-field gel electrophoresis and enterobacterial repetitive intergenic consensus PCR and biochemical tests to characterize Lactococcus garvieae. J Fish Dis 38: 37-47, 2015.

38. Fendri I, Ben Hassena A, Grosset N, Barkallah M, Khannous L, Chuat V, Gautier M and Gdoura R: Genetic diversity of food-isolated Salmonella strains through Pulsed Field Gel Electrophoresis (PFGE) and Enterobacterial Repetitive Intergenic Consensus (ERIC-PCR). PLoS One 8: e81315, 2013.

39. Adzitey F: Genetic diversity of Escherichia coli isolated from ducks and the environment using enterobacterial repetitive intergenic consensus. Pak J Biol Sci 16: 1173-1178, 2013.

40. Hulton CS, Higgins CF and Sharp PM: ERIC sequences: A novel family of repetitive elements in the genomes of Escherichia coli Salmonella typhimurium and other enterobacteria. Mol Microbiol 5: 825-834, 1991

41. Versalovic J, Koeuth T and Lupski JR: Distribution of repetitive DNA sequences in eubacteria and application to fingerprinting of bacterial genomes. Nucleic Acids Res 19: 6823-6831, 1991.

42. Zhang Q Cai L, Zhong G and Luo W: Simultaneous determination of jatrorrhizine, palmatine, berberine, and obacunone in Phellodendri Amurensis Cortex by RP-HPLC. Zhongguo Zhong Yao Za Zhi 35: 2061-2064, 2010 (In Chinese).

43. Berberine. Altern Med Rev 5: 175-177, 2000.

44. Yu HH, Kim KJ, Cha JD, Kim HK, Lee YE, Choi NY and You YO: Antimicrobial activity of berberine alone and in combination with ampicillin or oxacillin against methicillin-resistant Staphylococcus aureus. J Med Food 8: 454-461, 2005.

45. Kuo CL, Chi CW and Liu TY: The anti-inflammatory potential of berberine in vitro and in vivo. Cancer Lett 203: 127-137, 2004

46. Gu Y, Zhang Y, Shi X, Li X, Hong J, Chen J, Gu W, Lu X, Xu G and Ning G: Effect of traditional Chinese medicine berberine on type 2 diabetes based on comprehensive metabonomics. Talanta 81: 766-772, 2010.

47. Kulkarni SK and Dhir A: Sigma-1 receptors in major depression and anxiety. Expert Rev Neurother 9: 1021-1034, 2009.

48. Kulkarni SK and Dhir A: Current investigational drugs for major depression. Expert Opin Investig Drugs 18: 767-788, 2009.

49. Kulkarni SK and Dhir A: On the mechanism of antidepressant-like action of berberine chloride. Eur J Pharmacol 589: 163-172, 2008.

50. Kulkarni SK and Dhir A: Berberine: A plant alkaloid with therapeutic potential for central nervous system disorders. Phytother Res 24: 317-324, 2010. 